\title{
Efficiency analysis of an energy conversion system for a variable speed small hydropower plant
}

\author{
Tomasz Wegiel 1,a, Dariusz Borkowski ${ }^{1}$ and Damian Liszka² \\ ${ }^{1}$ Institute of Electromechanical Energy Conversion, Cracow University of Technology, Krakow, Poland \\ ${ }^{2}$ Research and Development Centre "Rader-Bis", Paczkow, Poland
}

\begin{abstract}
Present-day Small Hydropower Plants (SHPs) have a large development potential because of the increasing interest in renewable resources and distributed energy generation. However, the variable hydrological conditions that are found in the run-of-the-river projects require operations over a wide range of water flow and head variations. Special control methods and system topologies are needed to maintain the high efficiency of energy conversion systems. The synchronous generator excited by permanent magnets (PMSG) characterizes higher and more stable efficiency characteristic, in relation to the generated power, then mostly used in SHPs asynchronous machine. This paper investigates the efficiency of an example SHP solution. The researched system is based on an innovative generation unit (hydro-set) containing a propeller turbine integrated with the PMSG. In order to obtain the high efficiency in a wide range of water flow the variable speed operation method has been used. This solution requires a Power Electronic Unit in the energy conversion system to match the load and control the power flow from the generator to the grid. Efficiency analysis concerns all elements of the energy conversion system. Presented results comes from the real SHP of $150 \mathrm{~kW}$ nominal power.
\end{abstract}

\section{Introduction}

Small Hydropower Plants (SHPs) are the objects of a relatively small capacity that not exceed several MW. The investment effectiveness of the SHP depends mainly on the construction costs as well as on hydrological conditions of the specific location [1]. In general SHP are the low head "run-of-the-river" systems that are characterized by the low storage capacity of water. Due to the significant variation of the river hydrological conditions throughout the year SHP operation in the wide range of water flow is desired [2]. This condition may be fulfilled by the using of a double control of rotor blades and guide vanes, what is implemented in a Kaplan turbine. However, this mechanically complex solution, widely used in large systems, is expensive and economically not justified in SHPs. The energy conversion system of small and micro power plants bases on the simple turbine construction with a single control of the guide vanes, such as a Francis turbine and a propeller turbine. However, their efficiency depends considerably on the hydrological conditions (water head $H$ and flow $Q$ ) during the constant speed operation. The effective range of the energy conversion system under the hydrological fluctuations can be widen by implementing the variable speed operation of the turbine [3]. This technique may be obtained by using the power electronic converter (PEC) that match the electrical energy taken from the generator to the power system requirements [4].

\footnotetext{
a Corresponding author: tomasz.wegiel@pk.edu.pl
}

The important function of the PEC is the regulation of the turbine load torque by an electrical power flow control. This allows to control the turbine speed in the wide range from $40 \%$ up to $140 \%$ of the nominal speed. The synchronous generator excited by the permanents magnets (PMSG) is especially attractive in that type of application. Its main advantage comparing to the widely used induction machines is the high and more stable efficiency characteristic in relation to the generated power and the rotational speed [5-6]. Moreover, the construction of the synchronous generator allows to achieve a higher pair pole number what can eliminate the mechanical gear.

The hydropower plant costs are dominated by the construction process such as: power house building, inlet and outlet channel, etc. [1]. These costs may be significantly reduced by the using of water turbine integrated with generator (called hydro-set) [6]. This solution eliminates the necessity of extraction of the turbine shaft outside the turbine chamber. Furthermore, the overall dimensions of the hydro-set are reduced and the assembly operation is simplified and fasten.

The innovative solution of the SHP containing two integrated hydro-sets of $150 \mathrm{~kW}$ total power working with the variable speed is described in [6]. The current paper concentrates on the efficiency analysis of the specific elements of the energy conversion system. The hydro-set with the nominal parameters: $P_{\mathrm{NG}}=75 \mathrm{~kW}, U_{\mathrm{NG}}=500 \mathrm{~V}$, 
$n_{\mathrm{N}}=300 \mathrm{rpm}, \quad Q_{\mathrm{N}}=3 \mathrm{~m}^{3} / \mathrm{s}, \quad H_{\mathrm{N}}=3 \mathrm{~m}$ consisting of the permanent magnet synchronous generator, the propeller turbine and the guide vanes, cooperates with the separate $\mathrm{PEC}$ of $\mathrm{AC} / \mathrm{DC} / \mathrm{AC}$ type. The main target of this research is to highlight the advantages of the innovative solution comparing to the standard one commonly used in SHPs as well as indicate some negative sides.
The main elements of the energy conversion system of the innovative SHP solution are presented in Fig. 1.The elements that have the main influence on the total efficiency are the turbine integrated with generator and the power electronic converter. The control system decides about the energy conversion effectiveness under the actual hydrological conditions [6-8].

\section{Energy conversion system}

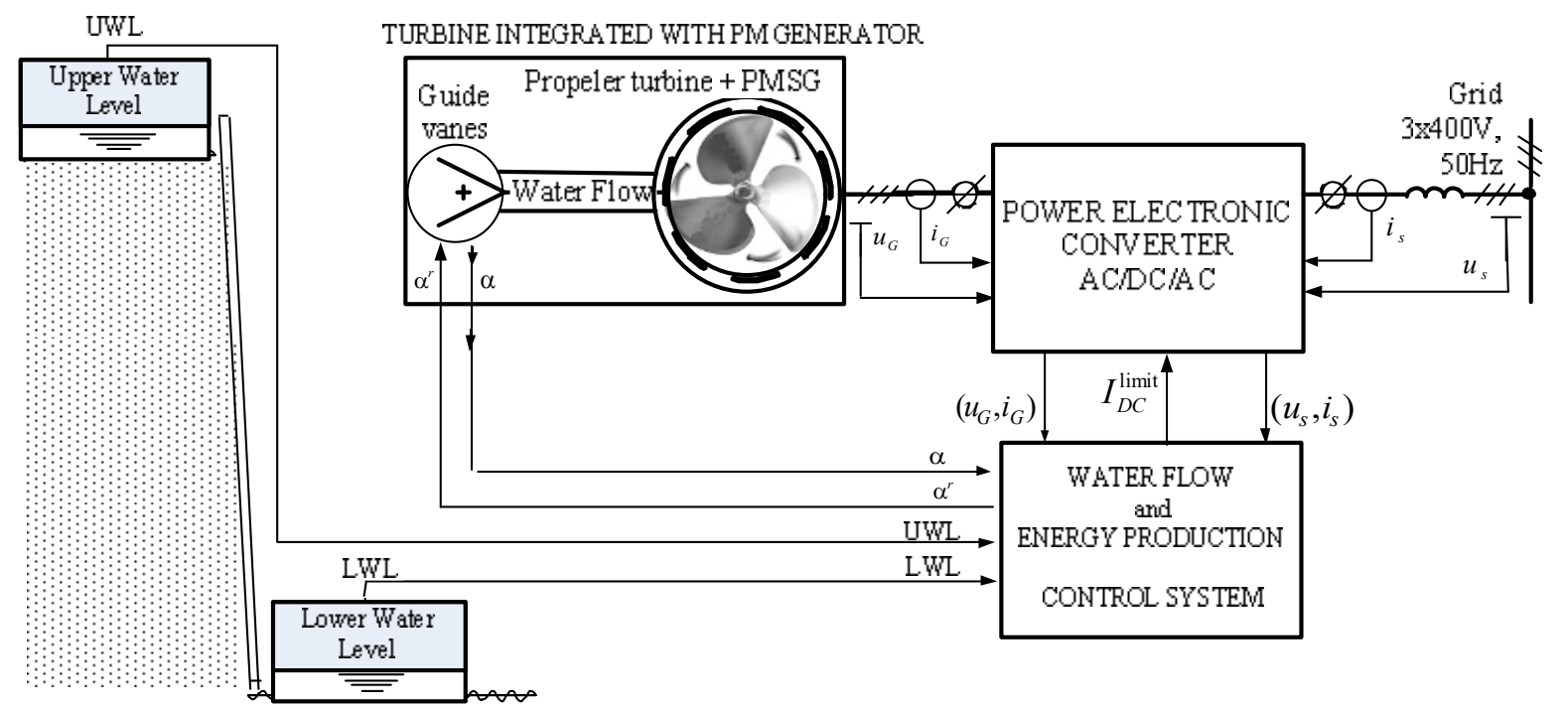

Figure 1. Energy conversion system structure.

\subsection{Hydro-set structure}

The hydro-set structure is based on the tubular construction (Fig. 2). The guide vanes controls the water flowing through the turbine and functioning also as a turbine closer by blocking the water in a turbine offstate. The generator stator has a classical 3-phase structure, whereas a magnetic circuit has to be designed according to the specific turbine dimensions (Fig. 3). The turbine parameters are calculated taking into account the nominal water head and flow of the specific power plant localisation. Additionally, the stator windings due to the electrical insulation have to be specially protected against water by the dedicated sealing compound. The turbine blades are situated in the generator rotor and fixed to the ring with permanent magnets (Fig 3 ).

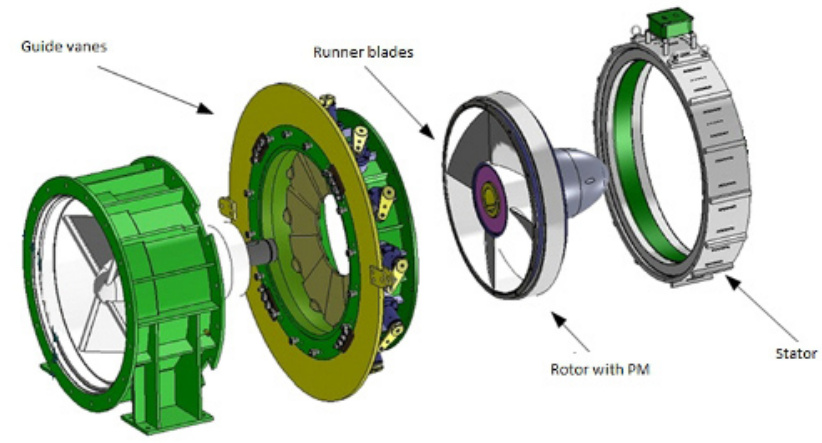

Figure 2. Components of the integrated hydro-set.

The ring replaces the shaft and transfers the mechanical torque from the turbine. Water flowing through the gap between the generator stator and rotor improves the cooling process of the stator windings. a.)

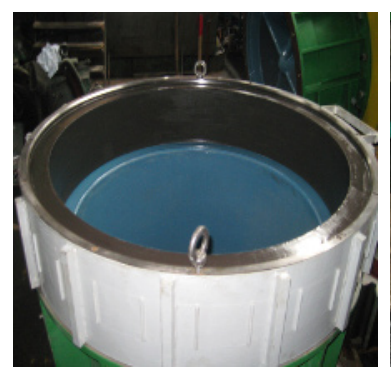

c.)

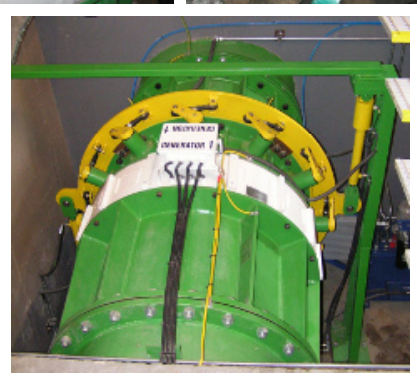

Figure 3. Components of the real hydro-set of $75 \mathrm{~kW}$ power: a.) stator, b.) rotor with turbine blades, c.) assembled hydro-set.

\subsection{Power electronic converter}

The power electronic converter (PEC) of $\mathrm{AC} / \mathrm{DC} / \mathrm{AC}$ type (Fig. 4, Fig. 5) performs two main functions in the presented energy conversion system. Firstly, it match the variable parameters of the electrical energy of synchronous generator with permanent magnets to the constant values of voltage and frequency required by the power system. The second task of the PEC is to control the power flow according to the actual hydrological conditions. Furthermore, this element 
maintains the proper electrical energy quality by minimising higher order harmonics of the PEC current from the grid and generator side. An interesting function is the regulation of a power factor and reactive power compensation of a local system [9]. The analogous PEC solutions are already known in the wind turbine systems. The most popular converter structure is the $\mathrm{AC} / \mathrm{DC} / \mathrm{AC}$ type [4]. The presented SHP uses the PEC with the DPCSVM algorithm (Virtual Flux-Direct Power Control with SVM modulator). The principle of an operation and the influence of given PEC parameters on the hydroset control process were described in [6].

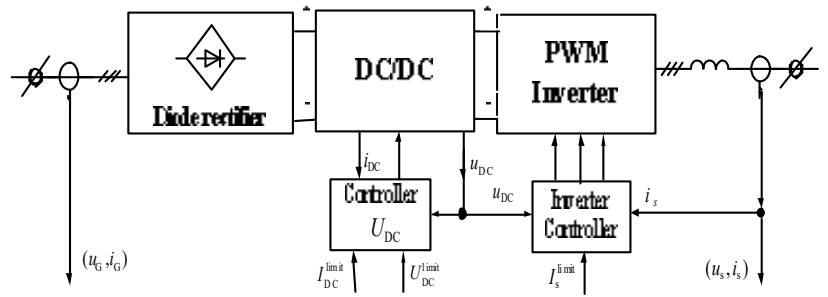

Figure 4. Block diagram of the power electronic converter.
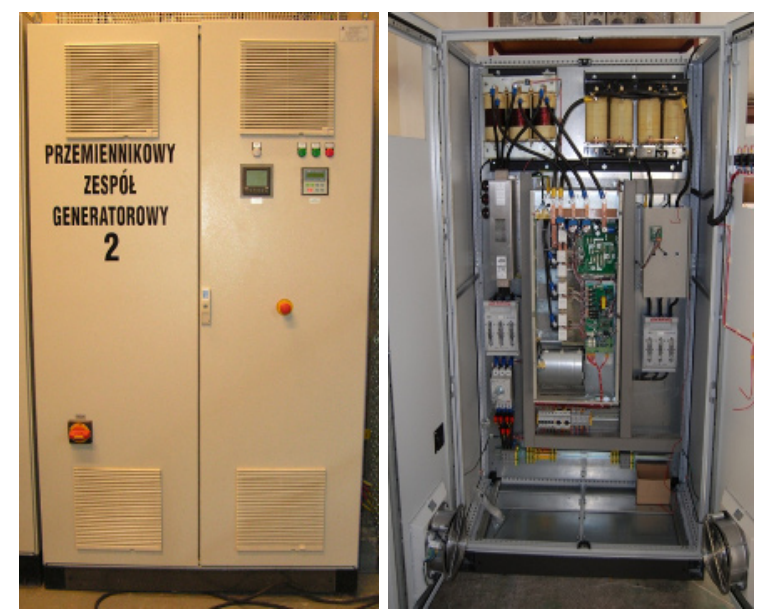

Figure 5. The view of the real power electronic converter of $90 \mathrm{~kW}$ power.

\subsection{Operation principles}

The basic characteristic that defines the turbine features and control possibilities is the power as a function of the rotational speed for a different angle of the guide vanes (Fig. 6).



Figure 6. Water turbine characteristics of power versus angular velocity for different angle of the guide vanes and $H=3.5 \mathrm{~m}$.
The main function of the turbine guide vanes in the "run-of-the-river" SHP is to control the water flow in order to keep the upper water on the constant level. The guide vane angle $\alpha$ influences the rotational speed by changing the turbine driving torque. In the presented solution the maximal power is achieved for the angle equals 60 degrees.

The second set of the control parameters influences the generator load current through the PEC. These are the limits of: the DC voltage $U_{\mathrm{DC}}^{\text {limit }}$, DC current $I_{\mathrm{DC}}^{\text {limit }}$ and $\mathrm{AC}$ current $I_{\mathrm{s}}^{\text {limit }}$ [6]. They allow to control the turbine load torque because the stator current of the synchronous generator is proportional to its torque.

The turbine can operate in any point of the area covered by the characteristics presented in Fig. 6 by the appropriate settings of the control parameters. The operation point selection is the crucial task of the control system. It has a significant influence on the system operation correctness, its efficiency and utilisation of the water potential.

\section{Efficiency analysis of the energy conversion system components}

\subsection{PM synchronous generator}

The synchronous generator excited by the permanent magnets has a higher efficiency in the wide range of the output power comparing to the induction generator. The efficiency curves in the power domain of the investigated synchronous generator and two example induction generators are presented in Fig. 7.

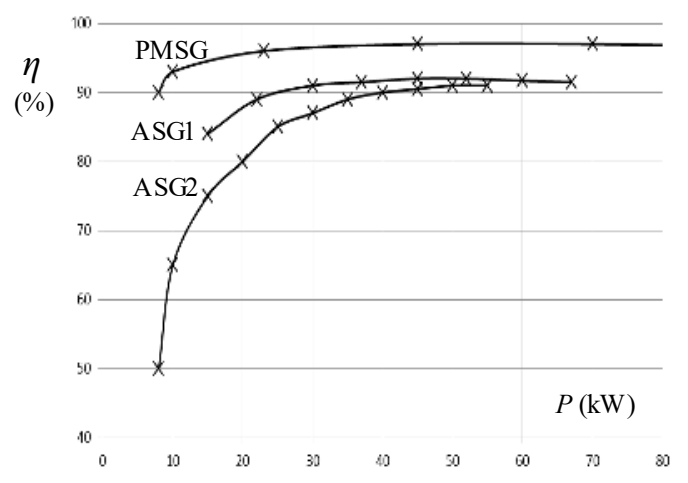

Figure 7. Comparison of the efficiency functions of the PM synchronous generator (PMSG) and two example induction generators (ASG1, ASG2) [10, 11].

It is clearly visible that the efficiency curve of the synchronous generator is higher and more stable in the wide range of the load variation than example induction generators. Similar situation takes place considering the rotational speed influence on the machine efficiency. The nominal efficiency given by the manufacturer equals $\eta_{\operatorname{maxGEN}}=97 \%$.

\subsection{Propeller turbine}

The total hydro-set efficiency depends mostly on the turbine efficiency, which is influenced by the rotational speed and water flow values significantly. This relation is defined by the turbine universal 
characteristic, known also as a hill chart. This figure (Fig. 8) presents the efficiency contour lines on the speed - water flow plane. The highest possible efficiency may be obtained by the changing the turbine speed according to the water flow variations (thick solid line). The relative increase of efficiency comparing to the constant speed operation (dotted line) is especially significant in the range of low water flow value. This relation is presented in Fig. 9. The nominal efficiency of the propeller turbine given by the manufacturer equals $\eta_{\max T \text { URB }}=80 \%$.

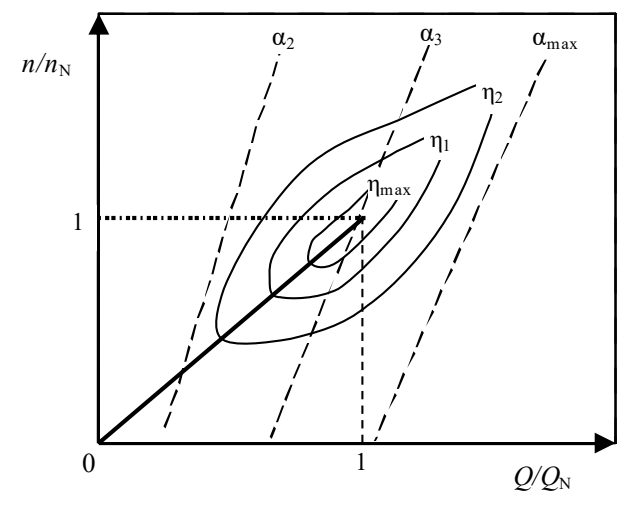

Figure 8. Universal characteristic of the propeller turbine ( $n-$ rotational speed, $Q$ - water flow).

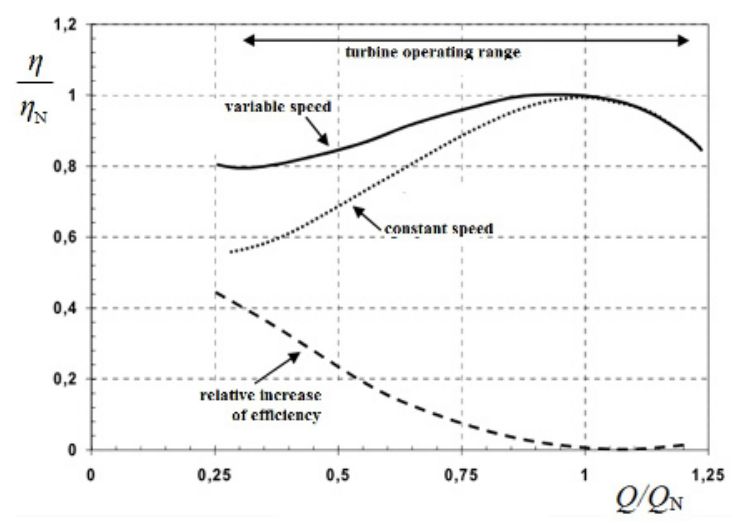

Figure 9. Efficiency curves for a different mode of turbine operation [10].

The second hydrological parameter that influences the turbine efficiency is the water head defined as a difference between the upper and the lower water levels. This relation concerning axial flow turbines is widely described in [12]. It is said, that the variable speed operation provides almost a constant turbine efficiency, independently of the head variations.

The features described above indicate that the variable speed operation improves the energy conversion effectiveness of the propeller turbine especially under the changeable hydrological conditions.

\subsection{Additional mechanical losses}

The integration of propeller turbine with generator results in the presence of water in the gap between the stator and rotor. This creates the additional power losses of the hydro-set causes by the fluid friction between the rotating elements. These losses can be significant similarly to the submersible motors where they are estimated at about $3-12 \%$ of the nominal power [13]. The theoretical analysis of this phenomena may be carried out basing on the two cylindrical model of the hydro-set. The calculations are performed using empirical formulas due to the phenomena complexity. The most likely used formula in that type of calculations is presented below.

$$
\Delta P=\lambda \cdot l \cdot D^{4} \cdot n^{3} \cdot 10^{-1}[\mathrm{~W}]
$$

where: $\quad \lambda$-hydraulic resistance coefficient,

$l$ - axial length of the gap [m],

$D$ - rotor diameter $[\mathrm{m}]$,

$n$ - rotational speed [rpm].

The hydraulic resistance coefficient depends on many factors, e.g. surface roughness, fluid temperature, pattern of the fluid flow. Its value can be determined using the Moody diagram basing on the relative roughness coefficient given by:

$$
\varepsilon=\frac{e}{\delta}
$$

where: $\quad e$-surface roughness [mm],

$\delta$ - gap height [mm],

and the Reynolds number, that characterizes the pattern of the fluid flow:

$$
\operatorname{Re}=\frac{\omega \cdot r \cdot \delta}{v}
$$

where: $\omega$-angular speed $\frac{n \cdot \pi}{30}\left[\frac{\mathrm{rad}}{\mathrm{s}}\right]$,

$r$ - rotor radius $D / 2[\mathrm{~m}]$,

$v$ - kinematic viscosity coefficient of water

in temp $15^{\circ} \mathrm{C}\left(v=1.13 \cdot 10^{-6}\left[\mathrm{~m}^{2} / \mathrm{s}\right]\right)$

Introducing the real hydro-set dimensions: $l=0.1 \mathrm{~m}$, $D=0.9 \mathrm{~m}, \delta=0.005 \mathrm{~m}$ and the surface roughness on the $0.001 \mathrm{~mm}$ level the value of the mechanical losses for different speed can be calculated (Table 1).

Table 1. Mechanical losses in the hydro-set gap

\begin{tabular}{|c|c|c|c|c|}
\hline$n[\mathrm{rpm}]$ & 100 & 150 & 200 & 300 \\
\hline $\operatorname{Re}$ & 20850 & 31275 & 41700 & 62550 \\
\hline$\lambda$ & 0.03 & 0.029 & 0.028 & 0.027 \\
\hline$\Delta P[\mathrm{~W}]$ & 196 & 642 & 1470 & 4780 \\
\hline
\end{tabular}

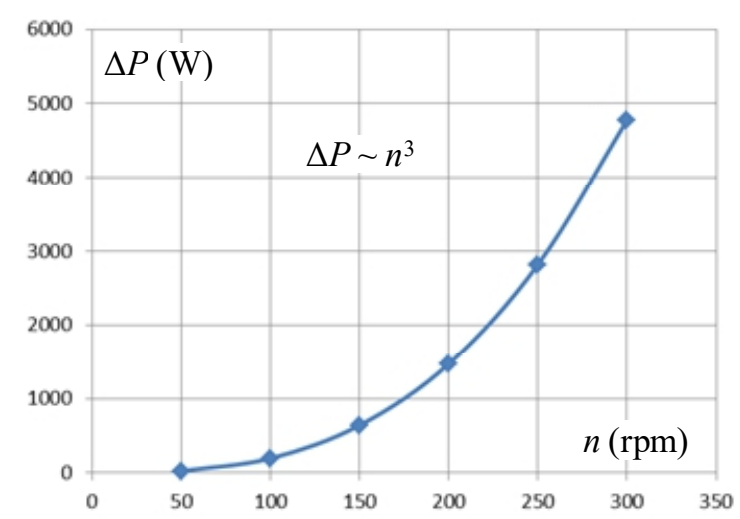

Figure 10. The mechanical losses in the hydro-set gap as a function of the turbine speed. 
The changes of Reynolds number caused by the angular speed variations does not influence the hydraulic resistance coefficient significantly. This observation leads to the conclusion, that the mechanical power losses in the gap is proportional to the cube of the rotational speed (Fig. 10).

As presented in Fig. 10, these losses can achieve a significant value and are estimated at about $6.4 \%$ of the nominal hydro-set power. It should be emphasized that this calculation concerns the ideal situation, it means that there is no static or dynamic eccentricity. Furthermore, the water contamination which can increase these losses is neglected.

\subsection{Power electronic converter}

The example time domain waveforms of voltages and currents of the generator and the PEC output are shown in Fig. 11.
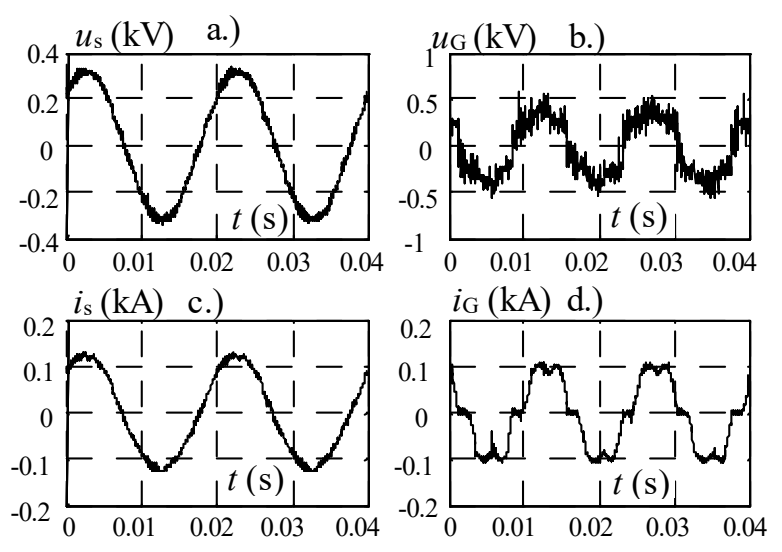

Figure 11. Example time domain waveforms of : a.) grid voltage, b.) generator voltage, c.) grid current, d.) generator current; for parameters: $n=298$ [rpm], $P=54.9[\mathrm{~kW}]$.

a.)

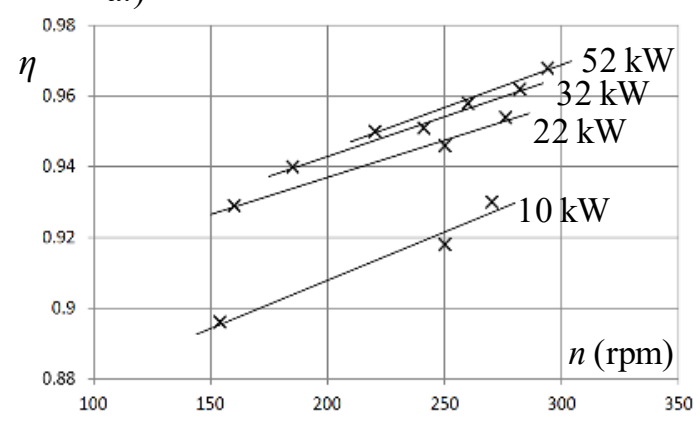

b.)

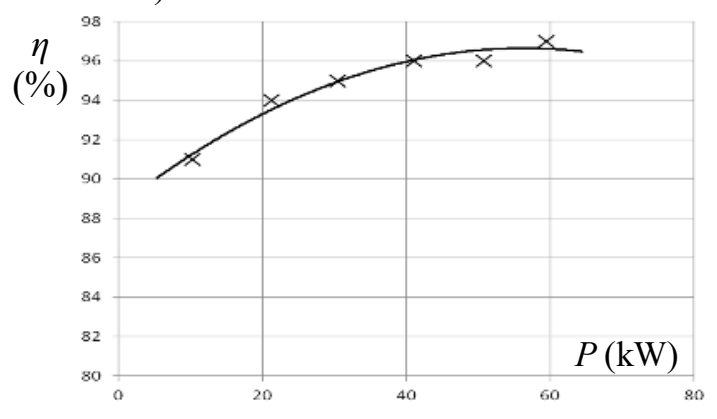

Figure 12. The PEC efficiency curves as a function of: a.) rotational speed of generator, b.) PEC active power.
The time domain signals of the grid are distorted by a low harmonic content and there is no phase shift between voltage and current. The generator signals contain significant harmonic distortion clearly visible in the waveforms. The generator current waveform is typical for systems fed by the diode bridge rectifier.

Presented signals of voltage and current can be used to calculate the input and output active power of the PEC and to define its efficiency.

The efficiency curves presented in Fig. 12 depend on the rotational speed. In order to keep the constant active power at the lower generator speed the current of the generator and PEC has to be increased. This causes the higher switching losses and conduction losses of the PEC. Higher losses at lower speed decreases the PEC efficiency (Fig. 12a).

Figure $12 \mathrm{~b}$ presents the curve of the average PEC efficiency as a function of the active power. The efficiency values for a power higher than $40 \mathrm{~kW}$ exceed $96 \%\left(\eta_{\operatorname{maxPEU}}=97 \%\right)$.

\section{Operating aspects}

The compact construction of the hydro-set facilitates its assembly on the power plant without an excessive building structure. This construction creates also some operation problems with an electrical insulation caused by the water presence in the gap between rotor and stator of the generator (Fig. 13). The isolation of the inside surface of stator has to be made from the non-conducting material due to edgy currents. The commercially available technologies allow to prepare the insulation that is waterproof. However the main problem concerns the abrasion resistance of such an insulation. The river is contaminated by the mud and sand that abrasive the surface of the stator and rotor. After about two years of the operation the hydro-set surface is damaged and the water leaks into the stator. The humidity migrates into the stator windings what may cause the breakdown of the electrical isolation (Fig. 13).

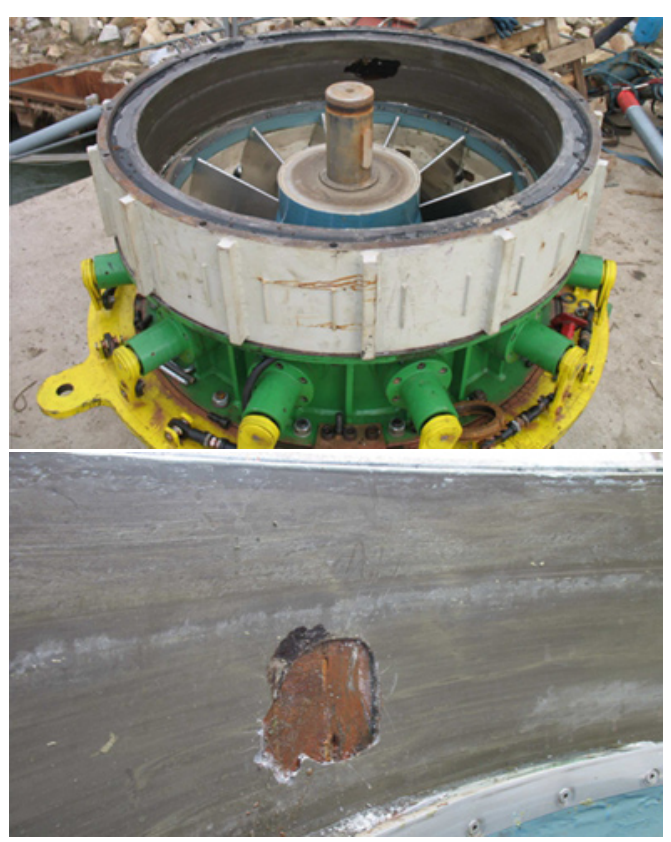

Figure 13. Insulation fault of the generator stator. 


\section{Conclusions}

This paper presents the efficiency analysis of the energy conversion system of the SHP that contains the innovative construction of the propeller turbine integrated with the permanent magnet synchronous generator. The maximal efficiency value (Table 2) is comparable with the standard solutions used in SHPs.

Table 2. The efficiency values of the individual components of the energy conversion system for chosen two operating points and the nominal hydrological parameters.

\begin{tabular}{|l|c|c|}
\hline \multicolumn{1}{|c|}{$\begin{array}{c}\text { Energy conversion } \\
\text { system components }\end{array}$} & $\begin{array}{c}\eta_{1} \\
n_{1}=150 \mathrm{rpm} \\
P_{1}=10 \mathrm{~kW}\end{array}$ & $\begin{array}{c}\eta_{\max } \\
n_{2}=300 \mathrm{rpm} \\
P_{2}=60 \mathrm{~kW}\end{array}$ \\
\hline Propeller turbine* & 0.55 & 0.74 \\
\hline $\begin{array}{l}\text { Permanent magnet } \\
\text { synchronous generator }\end{array}$ & 0.9 & 0.97 \\
\hline $\begin{array}{l}\text { Power electronic } \\
\text { converter }\end{array}$ & 0.91 & 0.97 \\
\hline Total efficiency & $\mathbf{0 . 4 5}$ & $\mathbf{0 . 7 0}$ \\
\hline
\end{tabular}

* - with gap losses included

The variable speed operation applied in this solution improves the efficiency under changeable hydrological conditions especially at low output power. Furthermore, the operation range is widen significantly (from $30 \%$ up to $120 \%$ of the nominal turbine discharge) what increase the yearly energy production. The simplification of the mechanical construction of the hydro-set by eliminating the shaft, gear transmission and control system of the turbine blades decreases the investment costs. The main disadvantage concerns the electrical insulation of the generator. Therefore, some further improvements need to be investigated. The dedicated sealing techniques that eliminate water from the gap have to be applied. The alternative solution to the presented one is the bulb unit where the standard generator is in the waterproof bulb submerged in the flow [14].

\section{References}

1. G.A. Aggidis, E. Luchinskaya, R. Rothschild, D.C. Howard, Renew Energ, 35 (2010)

2. A. Wijesinghe, Loi Lei Lai, DRPT Conf. P., China (2011)

3. J. Fraile-Ardanuy, J.R. Wilhelmi, J.J. Fraile-Mora, J.I. P'erez, IEEE T Energy Conversion, 21 (2006)

4. S. Nababan, E. Muljadi, F. Blaabjerg, PEDG Conf. P., Denmark (2012)

5. I. Boldea, Variable speed generators, CRS Press, Taylor \& Francis Group (2006)

6. D. Borkowski, T. Węgiel, IEEE T Energy Conversion, Vol. 28, 2 (2013)

7. W. Mazgaj, Z. Szular, T. Węgiel, T. Sobczyk, Przegląd Elektrotechniczny, 5 (2011)

8. T. J. Sobczyk, W. Mazgaj, Z. Szular, T. Węgiel, Archives of Electrical Engineering, vol. 60, 2 (2011)

9. D. Borkowski, EPE Conf. P., Czech Republic (2015)

10. W. Deprez, A. Dexters, C. Bastiaensen, F. Parasiliti, R. Belmans, EEMODS Conf. P, China, (2007)

11. B. Köhler, Fortschritt-Berichte VDI, Series 21 (Elektrotechnik), 256, Düsseldorf (1998)
12. D. Roberts, J. Bard, D. Shenhai, Hydropower and Dams, 2 (1998)

13. G. Sčastlivyj, W. Sjemak, G. Fedorenko, Pogružnyje asinchronnyje elektrodvigateli, Energoatomizdat, Moskva (1983)

14. P. J. Donalek, Power and Energy Society General Meeting, Pittsburgh (2008). 